\title{
Are attractive male crickets better able to pay the costs of an immune challenge?
}

Clint D Kelly, Melissa SC Telemeco, Amy L Toth, Lyric C Bartholomay

Reproduction and immunity are fitness-related traits that trade-off with each other. Parasite-mediated theories of sexual selection suggest, however, that higher-quality males should suffer smaller costs to reproduction-related traits and behaviours (e.g. sexual display) from an immune challenge because these males possess more resources with which to deal with the challenge. We used Gryllus texensis field crickets to test the prediction that attractive males should better maintain the performance of a fitnessrelated traits (e.g. calling effort) in the face of an immune challenge compared with unattractive males. We found no support for our original predictions. However, that immune activation causes attractive males to significantly increase their calling effort compared with unattractive males suggests that these males might terminally invest in order to compensate for decreased future reproduction. 


\title{
Are attractive male crickets better able to pay the costs of an immune challenge?
}

\author{
Clint D. Kelly ${ }^{1,3}$, Melissa Telemeco ${ }^{1,4}$, Amy L. Toth ${ }^{1}$, Lyric C. Bartholomay ${ }^{2,5}$
}

${ }^{1}$ Department of Ecology, Evolution and Organismal Biology

${ }^{2}$ Department of Entomology

Iowa State University, Ames, Iowa, USA 50011

Current address:

15 32Département des sciences biologiques, Université du Québec à Montréal, C.P. 8888 succursale

16 Centre-Ville, Montreal, QC H3C 3P8, Canada

17

${ }^{4}$ Science and Education Division, Pacific Science Center, Seattle, Washington, 98109, USA

${ }^{5}$ Department of Pathobiological Sciences, School of Veterinary Medicine, 305 Hanson

Biomedical Sciences Laboratories, University of Wisconsin-Madison, Madison WI 53706, USA

Keywords: immune challenge, sexual attractiveness, mate choice, sexual selection, life history 


\section{Abstract}

34 Reproduction and immunity are fitness-related traits that trade-off with each other. Parasite35 mediated theories of sexual selection suggest, however, that higher-quality males should suffer 36 smaller costs to reproduction-related traits and behaviours (e.g. sexual display) from an immune 37 challenge because these males possess more resources with which to deal with the challenge. We 38 used Gryllus texensis field crickets to test the prediction that attractive males should better 39 maintain the performance of a fitness-related traits (e.g. calling effort) in the face of an immune 40 challenge compared with unattractive males. We found no support for our original predictions. 41 However, that immune activation causes attractive males to significantly increase their calling 42 effort compared with unattractive males suggests that these males might terminally invest in 43 order to compensate for decreased future reproduction. 
44

45

46

47

48

49

50

51

52

53

54

55

56

57

58

59

60

61

62

63

64

65

66

67

68

69

70

71

72

73

74

75

76

77

78

79

80

81

82

83

84

85

86

87

88

\section{Introduction}

Individuals maximize fitness by balancing investment into reproduction with investment into other fitness-related traits, including immunity (Sheldon \& Verhulst, 1996; Viney, Riley \& Buchanan, 2005; Schmid-Hempel, 2011; Jacobs \& Zuk, 2011). Conflict between competing fitness-related traits means that allocation of resources toward immune function by an infected individual will reduce the resources available for other fitness-related traits, such as sexual display, and vice versa (McKean \& Nunney, 2001; Jacot, Scheuber \& Brinkhof, 2004; McKean \& Nunney, 2005; Leman et al., 2009; López, Gabirot \& Martin, 2009). Individuals will always face trade-offs when partitioning resources among competing functions (Schmid-Hempel, 2011; Jacobs \& Zuk, 2011). However, the relationship between competing functions can be either positive or negative when viewed across individuals. If individuals genetically vary more in their resource allocation than their genetic variation in resource acquisition (van Noordwijk \& de Jong, 1986), a trade-off will emerge among individuals because those that allocate more resources to sexual signals will have fewer resources available for immunity (Schmid-Hempel, 2011; Jacobs \& Zuk, 2011). For example, Skarstein and Folstad (1996) revealed that male Arctic charr (Salvelinus alpinus) with more-colourful sexual ornamentation had weaker immune function.

In contrast, if individuals genetically vary more in their ability to acquire resources than in their allocation of them, then positive genetic covariance between immune function and signal quality will emerge. Empirical evidence indicates that holding access to resources constant results in some individuals producing higher quality sexual signals than others (Wilkinson, Presgraves \& Crymes, 1998; Bortolotti et al., 2006; Karu, Saks \& Hõrak, 2007; Thomson, Darveau \& Bertram, 2014). Parasite-mediated theories of sexual selection (Schmid-Hempel, 2011; Jacobs \& Zuk, 2011) hypothesize that positive covariation between immune function and signal quality allow females to acquire indirect genetic benfits for their offspring through mate choice. A positive relationship between immunity and a sexondary sexual character has been demonstrated in several empirical studies (Saino \& Møller, 1996; López, 1998; Mougeot \& Redpath, 2004; Kelly \& Jennions, 2009; Schmid-Hempel, 2011; Jacobs \& Zuk, 2011). For example, Mougeot et al. (2004) found that the quality of a sexual ornament (redness of beak and eye rings) in male redlegged partridge (Alectoris rufa) positively correlated with greater swelling response to PHA.

A third pattern has also commonly been reported in the literature wherein individuals increase their investment in a fitness-related trait after an immune challenge. The 'reproductive compensation hypothesis' posits that immune-challenged individuals adpatively shift more of their resources into the current reproductive event because their residual reproductive value is reduced (Minchella \& Loverde, 1981; see also the terminal investment hypothesis: CluttonBrock, 1984). This hypothesis has been supported empirically in several studies (McCurdy, Forbes \& Boates, 2000; Agnew, Koella \& Michalakis, 2000; Reaney \& Knell, 2010; Kivleniece et al., 2010; Krams et al., 2011; Nielsen \& Holman, 2012; but see Kolluru, Zuk \& Chappell, 2002; Vainikka et al., 2007) with, for example, Polak and Starmer (1998) showing that male Drosophila nigrospiracula parasitized with mites court females at a significantly higher rate than unparasitized males. Although we know that an immune-challenge can increase reproductive investment, we know very little about how individual quality or sexual attractivenss mediates this effect.

Here, we investigate whether sexual attractiveness affects the performance of a sexual signal 
89 (calling frequency) after an immune challenge in the Texas field cricket, Gryllus texensis

90 (Orthoptera: Gryllidae). Mate choice studies have shown that sexually attractive male crickets

91 can have a particular pheromone profile (Tregenza \& Wedell, 1997), larger body size (Simmons,

92 1986b; Bertram \& Rook, 2012), call more frequently (Hunt et al., 2004), or have a calling song

93 with, for example, a higher chirp rate, longer intercall duration or louder amplitude (Wagner \&

94 Hoback, 1999; Holzer, Jacot \& Brinkhof, 2003; Scheuber, Jacot \& Brinkhof, 2003; Brooks et al.,

95 2005). Although most mate choice studies tend to examine only a small subset of male traits, it is

96 likely that female crickets simultaneously assess several traits when making their mate choice

97 (Simmons, 1986a; Shackleton, Jennions \& Hunt, 2005; Bussiere et al., 2006). The above-listed

98 male sexual signals, particularly those related to calling, are condition-dependent and

99 energetically costly to produce. Consequently, the quality of the signal tends to suffer when

100 males are forced to allocate resources to other fitness-related traits. For example, Jacot et al.

101 (2004) showed that an immune challenge with lipopolysaccharide (LPS) causes a significant

102 reduction in calling rate in male G. campestris and Fedorka and Mousseau (2007) observed a

103 post-challenge increase in interpulse interval in the calling song of male Allonemobius socius

104 ground crickets.

105 We used controlled laboratory experiments to test the sexual selection hypothesis that sexually

106

107

108

109

110

111

112

113

114

115

116

117

118

119

120

121

122

123

124

125

126

127

128

129

130

131

132

133

134 attractive males are better able to bear the costs of an immune challenge and thus maintain the performance of one component of sexual signalling, that is calling frequency, during immune activation. We predicted that immune-challenged attractive males would not suffer a significant decrease in calling frequency compared with control males whereas the calling effort of unattractive males would significantly decline relative to controls after an immune challenge. Alternatively, if sexual signaling trades off with immunity, we would expect that attractive males would suffer a significant drop in signalling relative to controls while unattractive males would not. If immune-challenged males undergo reproductive compensation then attractive and unattractive males should both elevate their sexual signalling relative to controls.

\section{Materials and Methods}

Experimental crickets were lab-reared descendants of individuals originally caught in Austin, TX (USA) in 2012 and 2013. The laboratory colony of crickets was reared in several large communal plastic bins $(73 \times 41 \times 46 \mathrm{~cm})$ until their penultimate instar at which time they were transferred to large sex-specific communal bins to prevent mating and ensure virginity. Newly eclosed adults were placed in individual $10 \mathrm{~cm}$ deli cups. All crickets were housed in an environmentally controlled room $\left(27^{\circ} \mathrm{C}, 12: 12 \mathrm{~h}\right.$ light:dark cycle, $80 \%$ relative humidity $)$ and were supplied with cotton-plugged water vials and dry cat food (Special Kitty Premium Cat Food) ad libitum. Crickets were used in experiments 10-14 d post-eclosion to ensure sexual maturity.

\section{Quantifying Attractiveness}

As in most gryllid species, mating in G. texensis follows a highly stereotypical sequence of behaviours. Males will contact a female with his antennae and then he will produce a courtship call during which he moves backward toward the female. If the female mounts the male he will attempt to attach an externally positioned spermatophore. Spermatophore transfer is accompanied by rapid and irregular flicking of the male's caudal cerci and takes 5-6 seconds, immediately after which the male unhooks his genitalia. Mating lasts 3 min on average and requires the active cooperation of the female to be successful. 
135 Latency to mate is a reliable predictor of male sexual attractiveness and mating success in field

136 cricket species (Simmons, 1987a; Bateman, 1998; Shackleton, Jennions \& Hunt, 2005; Bussiere

137 et al., 2006). Following Shackleton et al. (2005) we determined male attractiveness by

138 conducting a four-round no-choice tournament that indexed male attractiveness based on the

139 time that elapsed until a female mounted them. Studies have traditionally used a single trait to

140 assess male attractiveness in crickets (Heisler, 1985; Wedell \& Tregenza, 1999) but a no-choice

141 tournament is a superior approach because it simultaneously incorporates all relevant factors

142 contributing to short-range male attractiveness (Head et al., 2005; Shackleton, Jennions \& Hunt,

143 2005; Bussiere et al., 2006). For example, several studies on crickets have shown that male

144 attractiveness is unrelated to body size or measures of body condition only (e.g. Simmons,

145 1987b; Gray \& Eckhardt, 2001; Shackleton, Jennions \& Hunt, 2005). Tournaments commenced

146 at the onset of the environmental chamber's dark cycle and were conducted under red light to

147 minimize observer disturbance. In the first round, we placed each of 12 sexually naive males in

148 individual plastic containers (10 cm diameter) with a randomly assigned virgin female from our

149 stock culture and observed them until the female mounted the male. We scored a mounting as

150 successful if (1) the female remained motionless on top of the male for at least 3 seconds and (2)

151 the male commenced spermatophore transfer, characterized by the vibration of his cerci. Pairs

152 were separated prior to spermatophore transfer. Males were ranked 1 to 12 in order of mounting

153 (rank 1 being the fastest) and males that remained unmounted after 60 minutes were given the

154 average of the remaining ranks. This process continued for three more rounds with a new female

155 being assigned to each male in each round. Ranks from the four rounds were summed for each

156 male (four lowest sums were attractive; four highest sums were unattractive). Seven such

157 tournaments were completed yielding 28 attractive males (four lowest-ranked males from each

158 tournament) and 28 unattractive males (four highest-ranked males from each tournament).

\section{Administering an Immune Challenge}

160 We immune-challenged the attractive and unattractive males the day after the no-choice

161 tournaments by following protocols established for G. texensis (Adamo, 1999). Briefly, we cold-

162 anesthetized males by placing them on ice for 10 minutes and then injected them by inserting a

163 pulled-glass microcapillary needle (needles were used only once) along the left pleural region of

164 their abdomen. Microcapillary needles were made in a Flaming/Brown Micropipette Puller

165 (Sutter Instrument Co. model P-97, program 27) with Kwik-Fil's borosilicate glass capillaries.

166 Fourteen attractive males and 14 unattractive males were injected with $5 \mu \mathrm{L}$ of saline (phosphate-

167 buffered saline, Sigma-Aldrich), and 14 attractive males and 14 unattractive males were injected

168 with $100 \mu \mathrm{g}$ of lipopolysaccharide from Serratia marcescens (LPS, Sigma-Aldrich), dissolved in

$1695 \mu \mathrm{L}$ of saline. $S$. marcescens is a soil microbe that is frequently used as an immune challenge

170 model in $G$. texensis because it co-ocurrs with this cricket species in nature and is lethal to it

171 (Adamo, Jensen \& Younger, 2001). LPS is a non-pathogenic and non-living elicitor that

172 stimulates several pathways in the immune system of orthopterans (Jacot, Scheuber \& Brinkhof,

173 2004; Fedorka \& Mousseau, 2007; Leman et al., 2009) including G. texensis (Adamo, 1999).

\section{Quantifying sexual signaling}

175 One hour after males were injected (and at the onset of the dark cycle) they were put into a 230

$176 \mathrm{~mm} \times 155 \mathrm{~mm}$ x $170 \mathrm{~mm}$ plastic arena (Exo Terra Faunarium, Rolf C. Hagen Inc., Montreal,

177 Canada). We began recording calling frequency after $1 \mathrm{~h}$ because an immune challenge produces

178 measurable physiological effects in G. texensis after 90 minutes (Adamo et al., 2008); this

179 timeframe, therefore, ensured that we captured the full time period. The ventilated section of the 
180 lids were removed and replaced with a black mesh screen. The arena contained a paper shelter 181 (made from an Oxford 12.7 x $7.6 \mathrm{~cm}$ index card cut into 4 strips), one piece of Special Kitty cat 182 chow, and a water vial affixed with hot glue to a white paper lining the bottom. During each trial

183 a microphone (Dynex USB, DX-USBMIC13) was directed toward each male for 5 seconds every

184 five minutes to assess male calling. For each male, the microphone was held close to the mesh on

185 the top of its arena (within $23 \mathrm{~cm}$ of the male). We used QuickTime Player (version 10.2, Apple

186 Inc.) to visualize sounds detected by the microphone and recorded whether or not an individual

187 was calling $(0=$ no, $1=$ yes $)$ during each of the 605 second sample periods. The trials were

188 conducted in a dark room but to assist in appropriately placing the microphone near the focal

189 male, the arenas were illuminated with four CMVision IR200-940 (18 W) infra-red Illuminators

190 and visualized with a Canon Vixia HFG10 HD camcorder. Trials were 5 hours in duration and so

191 each male's calling was sampled for a total of 5 min over the course of 5 hours (i.e. sampled for

1925 seconds every 5 minutes for 5 hours). Trial duration was within the window of immune-

193 activation for LPS. Although LPS is cleared from insect haemolymph within hours (Kato et al.,

194 1994) it induces a prolonged up-regulation of some immune parameters in orthopterans (i.e. for a

195 period of days to weeks: Jacot et al., 2005; Fedorka \& Mousseau, 2007; Kelly, 2011; but see:

196 Adamo, 2004).

197

198

199

200

201

202

203

204

205

206

207

208

209

210

211

212

213

214

215

216

217

218

219

220

221

\section{Morphological Traits}

Immediately prior to being placed in a trial, males were weighed on a Denver Instruments TP-64 digital balance (to the nearest $0.01 \mathrm{~g}$ ) and the pronotum length measured using a stereoscope equipped with Leica LAS image analysis software (Leica Microsystems Inc., Buffalo Grove, IL, USA). Pronotum length (the distance from the anterior to posterior edges of the pronotum at the midline) is an excellent proxy for body size in G. texensis (Kelly, Tawes \& Worthington, 2014).

\section{Statistical Analysis}

The ability of males to bear the cost of an immune-challenge might be related to their body size or body mass (scaled to body size), and not to their attractiveness per se, because a larger body can potentially house a greater volume of hemolymph and immune-response substances (Zuk et al., 2004; Fedorka, Zuk \& Mousseau, 2004; Rantala \& Roff, 2006; Kelly \& Jennions, 2009). Therefore, we assessed whether body size or scaled mass differed between attractiveness groups and thus should be statistically controlled. We examined whether attractive males differed phenotypically from unattractive males by using one-way analysis of variance (ANOVA) to compare pronotum lengths (proxy for body size) and scaled mass indices (proxy for body condition). Body condition was calculated using the scaled mass index (SMI) following Kelly et al. (2014). We forgot to weigh and measure one unattractive and one attractive male prior to the experiment so the sample sizes differ between the morphological $(\mathrm{N}=54)$ and calling $(\mathrm{N}=56)$ analyses. A generalized linear model was used to test whether the fixed factors male attractiveness (attractive or unattractive), immune status (LPS- or saline-injected), and time since injection affected the number of calls (family=poisson). We pooled calling data into ten 30 minute bins for analysis. All statistical analyses were conducted in $R$ 3.2.3 (R Development Core Team, 2015) with data visualized using ggplot2 (Wickham, 2009). Means are given $\pm 1 \mathrm{SE}$ and $\alpha=0.05$.

222

223

\section{Results}


224 Attractive and unattractive males did not differ significantly in either pronotum length (one-way

225 ANOVA: $\mathrm{F}_{1,52}=0.001 \mathrm{p}=0.98$ ) or scaled body mass prior to experimental treatment (one-way

226 ANOVA: $\left.\mathrm{F}_{1,52}=0.361 \mathrm{p}=0.55\right)$.

227 We found a significant interaction between male attractiveness and immune status on calling

228 frequency (Table 1a; Figure 1). We explored this interaction further by examining the effect of

229 immune status on calling frequency separately within each attractiveness category. These

230 analyses found that attractive males called more frequently on average when injected with LPS

231 (8.36 \pm 2.74 calls $/ 5 \mathrm{~min}, \mathrm{n}=14)$ than with saline $(3.28 \pm 1.54, \mathrm{n}=14)$ (Table $1 \mathrm{~b})$ whereas LPS-

232 injected $(6.14 \pm 3.02, \mathrm{n}=14)$ and saline-injected $(8.64 \pm 3.39, \mathrm{n}=14)$ unattractive males did not

233 differ in their calling effort (Table 1c). Multiple comparisons using Holm's method showed that

234 saline-injected attractive males did not differ significantly from unattractive males that were

235 either saline-injected $(\mathrm{z}=-1.913, \mathrm{p}=0.223)$ or LPS-injected $(\mathrm{z}=0.698, \mathrm{p}=0.485)$. All males called

236 more frequently as trials progressed (Table 1).

237 Discussion

238 We found that an immune challenge had little statistical effect on the calling effort of

239 unattractive males whereas an immune challenge caused attractive males to increase their calling

240

241

242

243

244

245

246

247

248

249

250

251

252

253

254

255

256

257

258

259

260

261

262

263

264

265

266 frequency compared with saline-injected controls. This result does not support the sexual selection hypothesis that the calling effort of unattractive males should decline after an immune challenge while that of attractive males would not.

In contrast, that immune-challenged attractive males elevated their calling rate relative to controls supports the reproductive compensation hypothesis (see also the terminal investment hypothesis: Clutton-Brock, 1984): by increasing invesment in current fitness attractive males might compensate for their reduced future fitness. On the other hand, the lack of difference between control and treatment unattractive males does not support the reproductive compensation hypothesis. The observed similarity between saline- and LPS-injected unattractive males is counter-intuitive because immune-challenged unattractive males should have the poorest prospects for survival and, thus, the most to gain from increased investment in reproduction. Our results raise the question as to why attractive, but not unattractive, males were able to increase their calling effort post-challenge? Perhaps attractive males possessed a larger pool of resources from which to draw for use in both signalling and immunity compared with unattractive males. The scaled mass indices did not differ, on average, between the male attractiveness groups and suggests that the males in both groups had similar energetic reserves (i.e. fat load) and water content since these two variables scale positively with SMI (see Kelly, Tawes \& Worthington, 2014; Gray \& Eckhardt, 2001). Despite the similarity in these two components of scaled mass there might still have been important differences between the two attractiveness groups in their resource pools or the capacity to efficiently use their resources (Hill, 2011). For example, attractive males might have had more of a certain micronutrient that is critical to immune function or had better enzyme activity (see Thomson, Darveau \& Bertram, 2014). Thus, perhaps immune-challenged unattractive males are terminally investing, but since they have a poor resource pool from which to draw (or inefficient physiological mechanisms), that after allocating some portion of resources to immunity they can only achieve calling rates on par with healthy counterparts (i.e. they cannot increase calling rates relative to control males). 
267 Alternatively, perhaps unattractive male G. texensis invest in sexual signaling at the expense of survival (i.e. immunity) regardless of whether they are sick or healthy. In other words, unattractive males might adopt a strategy that resembles reproductive compensation (and terminal investment) simply given their poor prospects of acquiring mates and whether they recieve an immune-challenge makes little difference to their resource allocation strategy. This 'live fast, die young' hypothesis predicts that there should be little reproductive benefit to holding back resource consumption (e.g. via a reduced signaling rate) if caution yields no mates, and thus, no fitness gains. That unattractive males (both saline- and LPS-injected) in our study appear to call at a rate similar to that of healthy attractive males suggests that unattractive males are investing relatively heavily in signaling. This is likely not a general pattern across taxa as Hunt et al. (2004) found that it is high-quality, attractive male T. commodus crickets that invest in calling at the expense of longevity.

Both alternative explanations would benefit from an examinination of the investment in immunity by healthy and sick individuals with the prediction being that terminally-investing males should have a weaker immune response due to a shift of resources into current reproduction. However, Sadd et al. (2006) showed that immune-challenged males that were apparently terminally investing in current reproduction also had significantly higher phenoloxidase activity compared with unchallenged males.

We also found that time had a significant effect on calling effort with all males calling significantly more often as trials progressed over the course of our $5 \mathrm{~h}$ observation period. The lack of a significant treatment by time interaction suggests that males increase their calling effort independent of immune status or sexual attractiveness. Rost and Honneger (1987) also observed that $G$. campestris males in the wild increase their calling during the period from just after sunset to midnight. Similarly, Bertram et al. (2004) showed that wild-caught male G. texensis increase their rate of calling throughout the night and posited that this phenomena is an adaptive strategy because there is a greater abundance of acoustically-orienting parasitoid flies early in the evening and more abundant females later in the evening (Bertram, Xochitl Orozco \& Bellani, 2004). However, Bertram (2002) also showed that lab-reared males tend to call all night with only a small proportion calling more as night progresses. This latter study therefore suggests that perhaps the increased rate of calling that we observed throughout the night in our lab-reared population is due to crickets generally overcoming injection-related injuries.

Our study tested the hypothesis that sexually attractive (i.e. higher-quality) males suffer smaller costs to fitness-related traits from an immune challenge because these males possess more resources with which to pay such costs. We found that attractive males significantly increased their calling effort after an immune-challenge while an immune challenge had little effect on signaling in unattractive males. We suggest that our results might be explained by the reproductive compensation hypothesis but more testing is required to unequivocally support this conclusion.

\section{Acknowledgements}

We thank Sue Bertram, Felipe Dargent, and an anonymous reviewer for comments on a previous version of the manuscript. 
313

314

315

316

317

318

319

320

321

322

323

324

325

326

327

328

329

330

331

332

333

334

335

336

337

338

339

340

341

342

343

344

345

346

347

348

349

350

351

352

353

354

355

356

357

358

\section{References}

Adamo SA 1999. Evidence for adaptive changes in egg laying in crickets exposed to bacteria and parasites. Animal Behaviour 57:117-124.

Adamo SA 2004. Estimating disease resistance in insects: phenoloxidase and lysozyme-like activity and disease resistance in the cricket Gryllus texensis. Journal of Insect Physiology 50:209-216.

Adamo SA, Jensen M, Younger M 2001. Changes in lifetime immunocompetence in male and female Gryllus texensis (formerly G. integer): trade-offs between immunity and reproduction. Animal Behaviour 62:417-425.

Adamo SA, Roberts JL, Easy RH, Ross NW 2008. Competition between immune function and lipid transport for the protein apolipophorin III leads to stress-induced immunosuppression in crickets. Journal of Experimental Biology 211:531-538.

Agnew P, Koella JC, Michalakis Y 2000. Host life history responses to parasitism. Microbes and Infection 2:891-896.

Bateman PW 1998. Assortative mating by both sexes in the cricket Platygryllus primiformis (Orthoptera: Gryllidae; Gryllinae). Transactions of the American Entomological Society.

Bertram SM 2002. Short Communication: The influence of rearing and monitoring environment on temporal mate signaling patterns in the field cricket, Gryllus texensis. Journal of Insect Behavior 15:127-137.

Bertram SM, Rook V 2012. Relationship between condition, aggression, signaling, courtship, and egg laying in the field cricket, Gryllus assimilis. Ethology 118:360-372.

Bertram SM, Xochitl Orozco S, Bellani R 2004. Temporal shifts in conspicuousness: mate attraction displays of the texas field cricket, Gryllus texensis. Ethology 110:963-975.

Bortolotti GR, Blas J, Negro JJ, Tella JL 2006. A complex plumage pattern as an honest social signal. Animal Behaviour 72:423-430.

Brooks RC, Hunt J, Blows MW, Smith M, Bussiere LF, Jennions MD 2005. Experimental evidence for multivariate stabilizing sexual selection. 59:871-880.

Bussiere LF, Hunt J, Jennions MD, Brooks RC 2006. Sexual conflict and cryptic female choice in the black field cricket, Teleogryllus commodus. Evolution 60:792-800.

Clutton-Brock TH 1984. Reproductive effort and terminal investment in iteroparous animals. The American Naturalist 123:212-229.

Fedorka KM, Mousseau TA 2007. Immune system activation affects male sexual signal and reproductive potential in crickets. Behavioral Ecology 18:231-235.

Fedorka KM, Zuk M, Mousseau TA 2004. Immune suppression and the cost of reproduction in the ground cricket, Allonemobius socius. Evolution 58:2478-2485.

Gray DA, Eckhardt G 2001. Is cricket courtship song condition dependent? Animal Behaviour 62:871-877.

Head ML, Hunt J, Jennions MD, Brooks RC 2005. The indirect benefits of mating with attractive males outweigh the direct costs. PLoS Biology 3:e33.

Heisler IL 1985. Quantitative genetic models of female choice based on "arbitrary" male characters. Heredity 55:187-198.

Hill GE 2011. Condition-dependent traits as signals of the functionality of vital cellular processes. Ecology Letters 14:625-634.

Holzer B, Jacot A, Brinkhof MWG 2003. Condition-dependent signaling affects male sexual 
362

363

364

365

366

367

368

369

370

371

372

373

374

375

376

377

378

379

380

381

382

383

384

385

386

387

388

389

390

391

392

393

394

395

396

397

398

399

400

401

402

403

404

attractiveness in field crickets, Gryllus campestris. Behavioral Ecology 14:353-359.

Hunt J, Brooks RC, Jennions MD, Smith M, Bentsen C, Bussiere LF 2004. High-quality male field crickets invest heavily in sexual display but die young. Nature 432:1024-1027.

Jacobs AC, Zuk M 2011. Sex selection and parasites: Do mechanisms matter? In: Demas GE, Nelson RJ eds. Ecoimmunology. Ecoimmunology. Oxford, UK: Oxford University Press, 468-496.

Jacot A, Scheuber H, Brinkhof M 2004. Costs of an induced immune response on sexual display and longevity in field crickets. Evolution 58:2280-2286.

Jacot A, Scheuber H, Kurtz J, Brinkhof M 2005. Juvenile immune system activation induces a costly upregulation of adult immunity in field crickets Gryllus campestris. Proceedings of the Royal Society of London Series B Biological Science 272:63-69.

Karu U, Saks L, Hõrak P 2007. Carotenoid coloration in greenfinches is individually consistent irrespective of foraging ability. Physiological and Biochemical Zoology 80:663-670.

Kato Y, Motoi Y, Taniai K, Kadonookuda K, Hiramatsu M, Yamakawa M 1994. Clearance of lipopolysaccharide in hemolymph of the silkworm Bombyx mori: Its role in the termination of cecropin messenger-RNA induction. Insect Biochemistry and Molecular Biology 24:539545.

Kelly CD 2011. Reproductive and physiological costs of repeated immune challenges in female Wellington tree weta (Orthoptera: Anostostomatidae). Biological Journal of the Linnean Society 104:38-46.

Kelly CD, Jennions MD 2009. Sexually dimorphic immune response in the harem polygynous Wellington tree weta Hemideina crassidens. Physiological Entomology 34:174-179.

Kelly CD, Tawes BR, Worthington AM 2014. Evaluating indices of body condition in two cricket species. Ecology and Evolution 4:4476-4487.

Kivleniece I, Krams I, Daukšte J, Krama T, Rantala MJ 2010. Sexual attractiveness of immunechallenged male mealworm beetles suggests terminal investment in reproduction. Animal Behaviour 80:1015-1021.

Kolluru GR, Zuk M, Chappell MA 2002. Reduced reproductive effort in male field crickets infested with parasitoid fly larvae. Behavioral Ecology 13:607-614.

Krams I, Daukšte J, Kivleniece I, Krama T, Rantala MJ, Ramey G, Šauša L 2011. Female choice reveals terminal investment in male mealworm beetles, Tenebrio molitor, after a repeated activation of the immune system. Journal of Insect Science 11:56-14.

Leman JC, Weddle CB, Gershman SN, Kerr AM, Ower GD, St John JM, Vogel LA, Sakaluk SK 2009. Lovesick: immunological costs of mating to male sagebrush crickets. Journal of Evolutionary Biology 22:163-171.

López P, Gabirot M, Martin J 2009. Immune challenge affects sexual coloration of male Iberian wall lizards. Journal Of Experimental Zoology 311A:96-104.

López S 1998. Acquired resistance affects male sexual display and female choice in guppies. Proceedings of the Royal Society of London B: Biological Sciences 265:717-723.

McCurdy DG, Forbes MR, Boates JS 2000. Male amphipods increase their mating effort before behavioural manipulation by trematodes. Canadian Journal of Zoology 78:606-612.

McKean KA, Nunney L 2001. Increased sexual activity reduces male immune function in Drosophila melanogaster. Proceedings of the National Academy of Sciences of the United States of America 98:7904-7909.

McKean KA, Nunney L 2005. Bateman's principle and immunity: Phenotypically plastic reproductive strategies predict changes in immunological sex differences. Evolution 
405

406

407

408

409

410

411

412

413

414

415

416

417

418

419

420

421

422

423

424

425

426

427

428

429

430

431

432

433

434

435

436

437

438

439

440

441

442

443

444

445

446

447

448

449

450

59:1510-1517.

Minchella DJ, Loverde PT 1981. A cost of increased early reproductive effort in the snail Biomphalaria glabrata. The American Naturalist:876-881.

Mougeot FO, Redpath SM 2004. Sexual ornamentation relates to immune function in male red grouse Lagopus lagopus scoticus. Journal of Avian Biology 35:425-433.

Nielsen ML, Holman L 2012. Terminal investment in multiple sexual signals: immunechallenged males produce more attractive pheromones. Functional Ecology 26:20-28.

Polak M, Starmer WT 1998. Parasite-induced risk of mortality elevates reproductive effort in male Drosophila. Proceedings of the Royal Society of London B: Biological Sciences 265:2197-2201.

Rantala MJ, Roff DA 2006. Analysis of the importance of genotypic variation, metabolic rate, morphology, sex and development time on immune function in the cricket, Gryllus firmus. Journal of Evolutionary Biology 19:834-843.

Reaney LT, Knell RJ 2010. Immune activation but not male quality affects female current reproductive investment in a dung beetle. Behavioral Ecology 21:1367-1372.

Rost R, Honegger HW 1987. The timing of premating and mating behavior in a field population of the cricket Gryllus campestris L. Behavioral Ecology and Sociobiology 21:279-289.

Sadd BM, Holman L, Armitage H, Lock F, Marland R, Siva-Jothy MT 2006. Modulation of sexual signalling by immune challenged male mealworm beetles (Tenebrio molitor, L.): evidence for terminal investment and dishonesty. Journal of Evolutionary Biology 19:321325.

Saino N, Møller AP 1996. Sexual ornamentation and immunocompetence in the barn swallow. Behavioral Ecology 7:227-232.

Scheuber H, Jacot A, Brinkhof MWG 2003. Condition dependence of a multicomponent sexual signal in the field cricket Gryllus campestris. Animal Behaviour 65:721-727.

Schmid-Hempel P 2011. Evolutionary Parasitology. Oxford, UK: Oxford University Press.

Shackleton M, Jennions MD, Hunt J 2005. Fighting success and attractiveness as predictors of male mating success in the black field cricket, Teleogryllus commodus: the effectiveness of no-choice tests. Behavioral Ecology and Sociobiology 58:1-8.

Sheldon, Verhulst S 1996. Ecological immunology: costly parasite defences and trade-offs in evolutionary ecology. Trends in Ecology \& Evolution 11:317-321.

Simmons LW 1986a. Female choice in the field cricket Gryllus bimaculatus (De Geer). Animal Behaviour 34:1463-1470.

Simmons LW 1986b. Inter-male competition and mating success in the field cricket, Gryllus bimaculatus (de Geer). Animal Behaviour 34:567-579.

Simmons LW 1987a. Sperm competition as a mechanism of female choice in the field cricket, Gryllus bimaculatus. Behavioral Ecology and Sociobiology 21:197-202.

Simmons LW 1987b. Female choice contributes to offspring fitness in the field cricket, Gryllus bimaculatus (De Geer). Behavioral Ecology and Sociobiology 21:313-321.

Skarstein F, Folstad I 1996. Sexual dichromatism and the immunocompetence handicap: an observational approach using Arctic charr. Oikos 76:359.

Team RDC R: A Language and Environment for Statistical Computing.

Thomson IR, Darveau C-A, Bertram SM 2014. Body morphology, energy stores, and muscle enzyme activity explain cricket acoustic mate attraction signaling variation. PLoS ONE 9:e90409.

Tregenza T, Wedell N 1997. Definitive evidence for cuticular pheromones in a cricket. Animal 
$451 \quad$ Behaviour 54:979-984.

452 Vainikka A, Rantala MJ, Seppälä O, Suhonen J 2007. Do male mealworm beetles, Tenebrio

453

454

455

456

457

458

459

460

461

462

463

464

465

466 molitor, sustain the honesty of pheromone signals under immune challenge? Acta Ethologica 10:63-72.

van Noordwijk A, de Jong G 1986. Acquisition and allocation of resources: Their influence on variation in life-history tactics. The American Naturalist 128:137-142.

Viney ME, Riley EM, Buchanan KL 2005. Optimal immune responses: immunocompetence revisited. Trends in Ecology \& Evolution 20:665-669.

Wagner WE, Hoback W 1999. Nutritional effects on male calling behaviour in the variable field cricket. Animal Behaviour 57:89-95.

Wedell N, Tregenza T 1999. Successful fathers sire successful sons. Evolution 53:620.

Wickham H 2009. ggplot2: Elegant Graphics for Data Analysis. New York: Springer.

Wilkinson G, Presgraves D, Crymes L 1998. Male eye span in stalk-eyed flies indicates genetic quality by meiotic drive suppression. Nature 391:276-279.

Zuk M, Simmons LW, Rotenberry J, Stoehr A 2004. Sex differences in immunity in two species of field crickets. Canadian Journal of Zoology 82:627-634. 


\section{Figure caption}

469

470 Figure 1. Mean $( \pm \mathrm{SE})$ number of calls made by male $G$. texensis crickets during each of the ten 47130 min observation periods. Regression lines for each factorial combination were fit using a 472 mixed model (poisson family of errors) with male ID entered as a random effect. LPS-A = LPS473 injected attractive males $(\mathrm{n}=14)$; Saline- $\mathrm{A}=$ saline-injected attractive males $(\mathrm{n}=14)$; LPS-U = 474 LPS-injected unattractive males $(n=14)$; Saline- $U=$ saline-injected unattractive males $(n=14)$. 475 Data points and error bars are adjusted around each time period to avoid overlap. 
1

Calling bouts for attractive and unattractive males that were injected with either saline or LPS

Figure 1. Mean $( \pm S E)$ number of calls made by male $G$. texensis crickets during each of the ten 30 min observation periods. Regression lines for each factorial combination were fit using a mixed model (poisson family of errors) with male ID entered as a random effect. LPS-A = LPS-injected attractive males $(n=14)$; Saline- $A=$ saline-injected attractive males $(n=14)$; LPS-U = LPS-injected unattractive males $(n=14)$; Saline- $U=$ saline-injected unattractive males $(n=14)$.

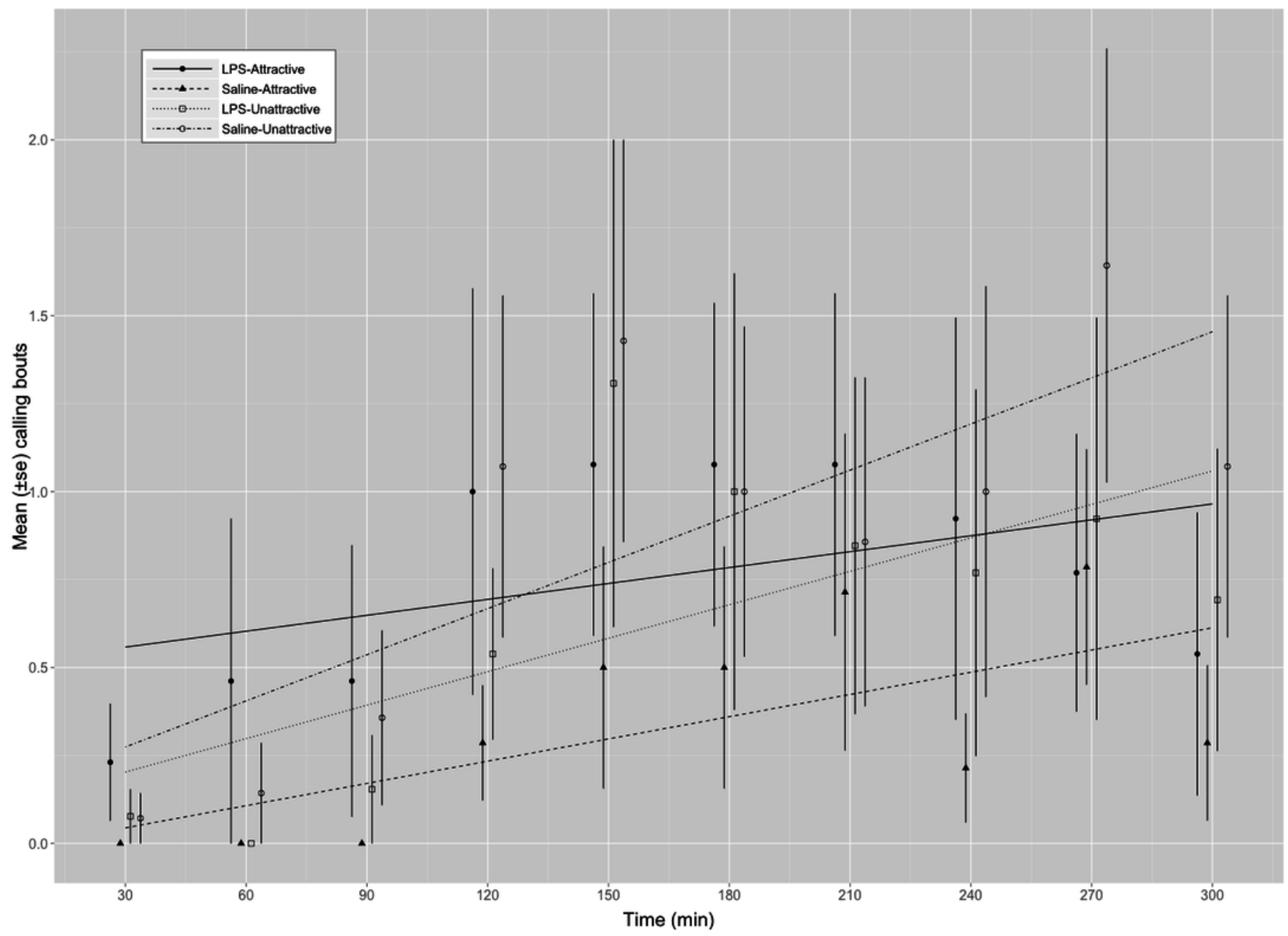




\section{Table $\mathbf{1}$ (on next page)}

Results for statistical models examining effect of experimental treatment on and male sexual attractiveness on calling effort.

Table 1. Results from models (see text) with $Z$ tests for estimated parameters. Values in bold are statistically significant at alpha $=0.05$. 
Table 1. Results from models (see text) with $Z$ tests for estimated parameters. Values in bold are statistically significant at alpha $=0.05$.

\begin{tabular}{|c|c|c|c|c|c|}
\hline Response & Predictor & $\beta$ & SE & $Z$ & $\mathrm{P}$ \\
\hline \multirow[t]{8}{*}{ a) Calling $(\mathrm{N}=56)$} & Intercept & -1.911 & 0.652 & -2.931 & 0.003 \\
\hline & Attractiveness(Un) & -1.855 & 0.984 & -1.886 & 0.059 \\
\hline & Immune status( $\mathrm{Sa})$ & -2.056 & 1.012 & -2.033 & 0.042 \\
\hline & Time & 0.004 & 0.001 & 3.205 & 0.001 \\
\hline & Immune status(Sa):Attractiveness(Un) & 3.224 & 1.425 & 2.263 & 0.024 \\
\hline & Immune status( $\mathrm{Sa})$ :Time & 0.003 & 0.002 & 1.516 & 0.130 \\
\hline & Attractiveness(Un):Time & 0.002 & 0.002 & 1.374 & 0.170 \\
\hline & Immune status(Sa):Attractiveness(Un):Time & -0.004 & 0.003 & -1.419 & 0.156 \\
\hline \multirow[t]{4}{*}{ b) Attractive males $(\mathrm{N}=28)$} & Intercept & -1.773 & 0.563 & -3.15 & 0.001 \\
\hline & Immune status $(\mathrm{Sa})$ & -1.942 & 0.881 & -2.204 & 0.027 \\
\hline & Time & 0.003 & 0.001 & 3.205 & 0.001 \\
\hline & Immune status(Sa):Time & 0.003 & 0.002 & 1.516 & 0.129 \\
\hline \multirow[t]{6}{*}{ c) Unattractive males $(\mathrm{N}=28)$} & Intercept & & & & $1.88 \times 10^{-}$ \\
\hline & & -4.074 & 0.952 & -4.278 & 05 \\
\hline & Immune status $(\mathrm{Sa})$ & 1.298 & 1.152 & 1.127 & 0.260 \\
\hline & Time & & & & $1.12 \times 10^{-}$ \\
\hline & & 0.005 & 0.001 & 4.392 & 05 \\
\hline & Immune status(Sa):Time & -0.000 & 0.001 & -0.378 & 0.705 \\
\hline
\end{tabular}

